\title{
Comparison of Two Stair Climbing Protocols for Smokers
}

Research Article

\author{
Gimenez $\mathrm{M}^{1}$, Saavedra $\mathrm{P}^{2}$, Eva M Lantarón ${ }^{3}$, Tran J ${ }^{4}$, Martín $\mathrm{N}^{1}$, Bach JR ${ }^{5}$
}

${ }^{1}$ Departamentos de Medicina Física y Rehabilitación y de Fisioterapia Respiratoria, Hospital Universitario de Gran Canaria Dr. Negrín, Bco de la Ballena s/n, Universidad de Las Palmas de Gran Canaria, Spain.

${ }^{2}$ Departamento de Matemáticas e Informática, Campus Universitario de Tafira, Universidad de Las Palmas de Gran Canaria, Spain.

${ }^{3}$ Facultad de Fisioterapia. Universidad de Vigo, Spain.

${ }^{4}$ Madonna Rehabilitation Hospital, Lincoln Nebraska, USA.

${ }^{5}$ New Jersey Medical School Rutgers, Newark, New Jersey, USA.

\section{Abstract}

Objectives: Compare two stair climbing protocols with each other and with an established cycle-ergometry protocol for smokers.

Methods: In an exercise physiology laboratory, 25 smokers' maximal O2 consumption (VO2max) was determined by cycleergometry at $30 \mathrm{~W} / 3$ min increments. Then, randomly they performed either maximal fixed intensity (FiSC) or bi-level intensity (BiSC) stair-climbing protocols at the same pace to exhaustion, before crossing-over to perform the other 1 to 3 days later. The sequence was repeated 6 weeks later. The FiSC was performed on a 10 flight staircase. The BiSC was performed by repeatedly climbing and descending a single flight. Outcome measures were exertional dyspnea (ED), leg pain (LP), respiratory rate $(\mathrm{RR})$, heart rate $(\mathrm{HR})$, peripheral pulse oximetry $(\mathrm{SpO} 2)$, blood pressure, physiologic cost index $(\mathrm{PCI})$, and self-reported preferences.

Results: All 25 subjects climbed the single-flight BiSC 10 times but no one could climb more than 8 consecutive flights (FiSC). Eighty to $95 \%$ of heart rate at VO2max was achieved by both, but the BiSC was significantly better tolerated over ten flights with significantly lower HR (<.001), PCI (<.001), ED and LP ( $\mathrm{p}<0.05)$, and higher RR $(<.001)$ and SpO2 (<.004). In addition, using only one flight was more practical, for both de subjects himself and for surveillance by the medical staff to control the speed of climbing, and the subjective and cardio respiratory responses.

Conclusion: The protocol of Bi-level exercise repeatedly climbing one flight of stairs is more practical, effective, and better tolerated than that of continuous stairs climbing.

Keywords: Maximal Stair Climbing Test; Pulmonary Rehabilitation; Aerobic Exercise; Cycle Ergometry; Endurance.

\section{Introduction}

Morbidity and mortality due to smoking decrease life expectancy an average of 7 years [1]. Obesity further decreases it. Exercise can reduce the untoward physical and psychosocial effects associated with both risk factors [1, 2]. Yet, only $20 \%$ of American adults perform recommended amounts of exercise [1].

Structured exercise rehabilitation programs of six to eight weeks duration have been shown to improve quality of life, increase exercise tolerance, and boost maximal oxygen consumption $\mathrm{VO}_{2}$ $\max )$ by $20 \%$ to $60 \%$ [3-5]. Although benefits can be maintained by 45 minutes of daily maximal training on a cycloergometer [35], most people stop exercising after discharge from the program $[4,5]$. Lack of time, motivation, and money to purchase equipment are often cited as the main barriers [6].

Low-tech and low cost training modalities (e.g., walking and twostep stool [7]) have been explored as alternatives to expensive ergometers and treadmills $[6,8,9]$ Staircases are potentially costeffective options [8]. Stair climbing can be easily incorporated into city dwellers' daily routines and used for exercise assessments [6-8]. Existing stair climbing protocols vary greatly though, and the lack of target reference values has limited widespread adop-

\section{*Corresponding Author:}

Manuel Gimenez,

Departamentos de Medicina Física y Rehabilitación y de Fisioterapia Respiratoria, Hospital Universitario de Gran Canaria Dr. Negrín, Bco de la Ballena s/n, Universidad de E-35020- Las Palmas de Gran Canaria, Spain.

E-mail: gimen3@hotmail.com

Received: December 05, 2016

Accepted: January 09, 2017

Published: January 10, 2017

Citation: Gimenez M, Saavedra P, Eva M Lantarón, Tran J, Martín N, et al., (2017) Comparison of Two Stair Climbing Protocols for Smokers. Int J Resp Dis Care Med. 2(1), 8-13. doi: http://dx.doi.org/10.19070/2577-4409-170003

Copyright: Gimenez $\mathbf{M}^{\odot}$ 2017. This is an open-access article distributed under the terms of the Creative Commons Attribution License, which permits unrestricted use, distribution and reproduction in any medium, provided the original author and source are credited. 
tion [6-9]. A second barrier can be insufficient stairs to climb. Physiologic benefits of using short flights of stairs have not been studied.

The objective of this study were to compare two stair climbing protocols with an established cycle-ergometry protocol for smokers.

\section{Materials and Methods}

This study was approved by the institution's ethics committee and was conducted according to Declaration of Helsinki standards. All potential study subjects except for one gave informed consent. Thus, there were 25 subjects.

Unmedicated, active male smokers, with a history of 20 to 24 pack-years ( 1 pack-year $=20$ cigarettes $/$ day x 1 year), were recruited. Inclusion criteria were: age 18 and older, absence of bronchoconstriccion based on the European Community for Steel and Coal questionnaire [10] and observation at rest and during exercise to $\mathrm{VO}_{2}$ max on cycle-ergometry [11]. Exclusion criteria were insufficient cardiopulmonary, neuromuscular, medical, or physical capacity to permit strenuous exercise, abnormal spirometry, chest radiographs or electrocardiogram $[10,11]$, evidence of bronchoconstriccion or not signing consent. A target sample size of 25 was pre-determined to achieve $80 \%$ power.

The maximum of three measurements was recorded for slow vital capacity, forced expiratory volume in the first second and maximum voluntary ventilation. Minute ventilation; tidal volumes; respiratory rate; and respiratory exchange, that is, oxygen uptake $\left(\mathrm{VO}_{2},\right)$ and carbon dioxide output $\left(\mathrm{VCO}_{2}\right)[5,7]$, were measured during the maximal exercise on cycleergometer protocol by Jaeger's Oxycon Champion (Jaeger GmdH \& Co., Wurzburg, Germany) calibrated before and after each use $[5,11]$. A bronchodilator (i.e. Salbutamol $0.2 \mathrm{mg}$ ) was administered for a second round of measurements to assess the absence of bronchoconstriction.

The cycle-ergometry was performed on the 1000 S (Medifit Inc, Maarn, the Netherlands) at increments of 30 watts/3 minute with cardiac monitoring (Multiscriptor EK; Hellige-France Inc, Strasbourg, France) $[5,11]$. The peak work rate (PWR) was that achieved during the last full $3 \mathrm{~min}$ before exhaustion to determined $\mathrm{VO}_{2}$ max and the Ventilatory Anaerobic Threshold (VAT) $[5,11]$. The $\mathrm{VO}_{2}$ max was recorded as the $\mathrm{VO}_{2}$ over the last 30 sec before exhaustion $[5,11]$. Oxygen pulse $\left(\mathrm{O}_{2} \mathrm{P}=\mathrm{VO}_{2} / \mathrm{HR}\right)$ was calculated at rest and at each ergometry increment. Dyspnea, leg pain [12], pulse oxyhemoglobin Saturation \% $\left(\mathrm{SpO}_{2}\right)$, and heart rate were monitored to calculate the PCI [7].

Once the targeted heart rates $\mathrm{VO}_{2}$ max were determined, the subjects began the stair climbing protocols 1 to 3 days later. They were randomly assigned to either FiSC or BiSC before crossing over. A 10-story building was used for the FiSC with uniform 3 meter flights with handrails. There were 20 steps on each flight with steps of $15 \mathrm{~cm}$ in height and $25 \mathrm{~cm}$ in breadth. A single flight with the same step dimensions was used for BiSC.

The subjects were instructed to climb until exhaustion. The FiSC and BiSC stair climbing rates were standardized to $12 \mathrm{sec}$ per flight paced by metronome $[7,11]$. The FiSC subjects rested 18 sec between flights to undergo clinical assessment for a total of $30 \mathrm{sec}$ per flight. The BiSC subjects descended the flight in $8 \mathrm{sec}$ paced by a metronome followed by $10 \mathrm{sec}$ of rest for clinical assessment for $30 \mathrm{sec}$ total per flight. The total number of consecutive flights or each protocol was recorded (Figure 1).

During the stair climbing exertional dyspnea and leg pain were measured by modified Borg scale [12], a 0-10 Likert scale with 10 representing most severe [12], after each flight of the FiSC and BiSC as well as after the cycleergometer exercise at PWR [5].

Blood pressures were measured at the end of all these maximal tests. Pulse Oximetry, heart rate, respiratory rate, exertional dyspnea and leg pain were measured $10 \mathrm{~min}$ before the tests and after each flight of the FiSC and BiSC. A physiatrist and a physiotherapist collected the data during the rest periods [12].

Six weeks later, to minimize the risk of learning effects and training on the initial performances of FiSC and BiSC, the 25 subjects crossed over to repeat the sequence in reverse order on subsequent days and were subsequently asked to compare FiSC and BiSC for tolerability and subjective intensity.

The measured responses were summarized as means and standard deviations or medians and interquartile ranges (IQR) based on the data distribution [13]. T-test and Wilcoxon test for independent variables were used to compare FiSC and BiSC data [14]. Statistical significance was set at $\mathrm{p}<0.05$. The arterial blood pressure and heart rate values at rest, after the $10^{\text {th }}$ floor of the BiSC, the $8^{\text {th }}$ floor of the FiSC and at PWR of the incremental cycle ergometry were compared. The means were also estimated by means of confidence intervals at $95 \%$. All statistical analyses were performed using the $\mathrm{R}$ package, version 3.0.1 (R Development Core Team, 2013) [14].

Figure 1. The Stair Climbing Protocols.
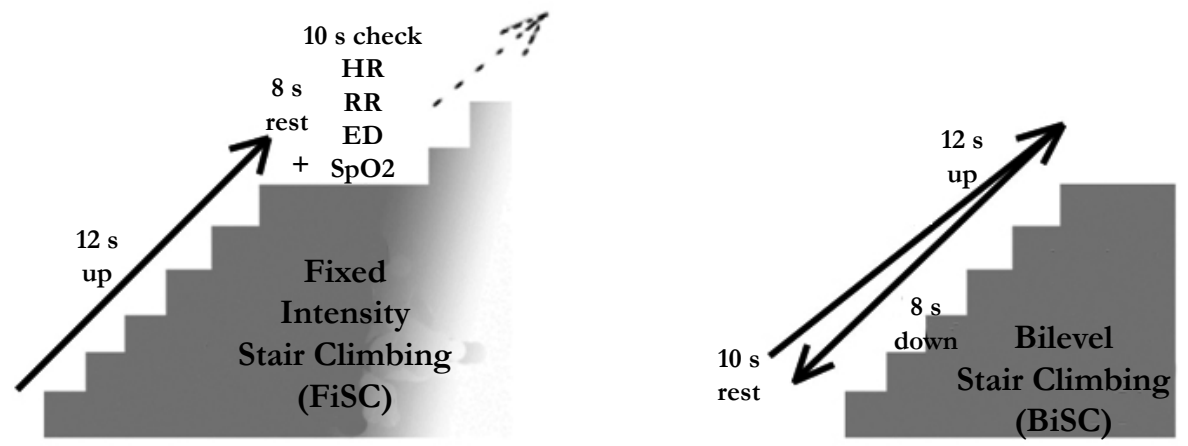


\section{Results}

Of the 25 subjects aged 39 to 66 none could climb more than 8 flights on the FiSC but all could on the BiSC protocol (Figure. 2 and 3). All subjects reached from 80 to $95 \%$ of the $\mathrm{VO}_{2}$ max $\mathrm{HR}$ they had attained by cycle-ergometry $[5,11,15]$.

Table 1 summarizes the subjects' demographics, pulmonary function, and cycle-ergometry results.

Figures 2 and 3 demonstrate changes in heart rate, respiratory rate, PCI, exertional dyspnea, and leg pain as a function of flights climbed during FiSC and BiSC. Note that the maximal level of exercise was achieved at the $10^{\text {th }}$ flight for BiSC and the $8^{\text {th }}$ flight for FiSC. There were differences in physiological parameters including in self-reported leg pain and dyspnea.

Table 2 demonstrates that while there was no difference in the BiSC 10 flight performance parameters, when measured after 6 weeks, FiSC 8-flight performance were significantly different for respiratory rate, oxyhemoglobin saturation, and exertional dyspnea. The comparison BiSC over FiSC (**p of Table 2 ) shows that all except one (ED) of the variables are differents; Table 3 further demonstrates that while heart rates and blood pressures increase significantly during exercise $(\mathrm{p}<0.001)$ the increases in heart rate and in systolic blood pressures after 10-floor climb of the BiSC were significantly less than the increases seen in the 8-flight FiSC and with maximal cycle-ergometry (PWR, $\mathrm{p}<0.05$ ). Indeed, the increases in heart rates and blood pressure during the 8-flight FiSC were even significantly greater than those seen with maximal cycle-ergometry (PWR, $\mathrm{p}<0.05)$. While the diastolic blood pressures were highest at rest $(\mathrm{p}<0.05)$, it was during the 8 -flight FiSC and the cycle-ergometry that the values of diastolic blood pressure increased the most $(\mathrm{p}<0.05)$.
Table 4 shows the results of a post-study stair climbing questionnaire comparing the BiSC and FiSC with the corresponding p.

\section{Discussion}

Achieving a heart rate at 80 to $95 \%$ of that at the $\mathrm{VO}_{2}$ max demonstrates that stair climbing can be high intensity exercise. All subjects climbed $20 \%$ more flights using the BiSC $(p<0.05)$; it was better tolerated and achieved aerobic levels of exercise by permitting exercise close to $\mathrm{VO}_{2}$ max at lower heart rates, blood pressure, and dyspnea and at higher respiratory rates, and peripheral oxyhemoglobin saturation $\left(\mathrm{SpO}_{2}\right.$, Table 2, $\left.\mathrm{p}<0.05\right)$, In addition, it was preferred by the subjects (Table 4).

Thus, stair climbing can provide economical aerobic training without specialized equipment [17-20] and has been recommended to alleviate America's and Europe's obesity epidemic [1, 6, 9, 17]. However, studies to date have been limited by heterogeneity of stair climbing protocols and inadequate control of confounding factors $[9,17-20]$. This study overcame some of these limitations. First, this was a homogenous group of 25 highly motivated unmedicated active male smokers of similar age and health status with similarly low maximal exercise capacity because of smoking $[5,11]$. There were strict inclusion criteria. The subjects were methodically instructed and the exercise strictly regimented. Individual $\mathrm{VO}_{2}$ max parameters were verified by cycle-ergometry. A fixed stair climbing rate was implemented $[7,11]$. In addition, the protocols were repeated to ensure reproducibility, especially on the BiSC.

Bi-level walking and cycling exercises have been reported to have achieved greater $\mathrm{V}_{\mathrm{E}}$ and $\mathrm{VO}_{2}$ for healthy subjects [11, 21, 22], people with chronic obstructive pulmonary disease (COPD)[11, 23], and in pulmonary and cardiac transplant patients than has fixed intensity exercise [19, 24-27]. Our comparisons of BiSC with FiSC over 8 flights were consistent with this. The BiSC pro-

Figure 2. Heart rate, Respiratory Rate, and Physiological Cost Index Changes by Flight.
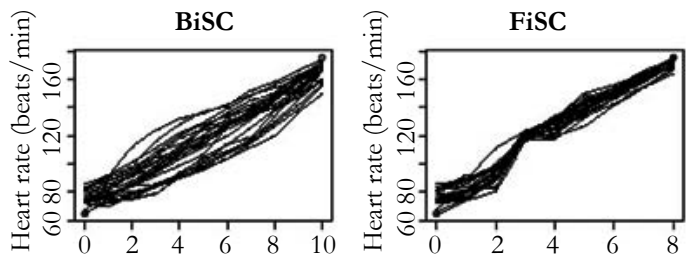

Number of Floors Climbed

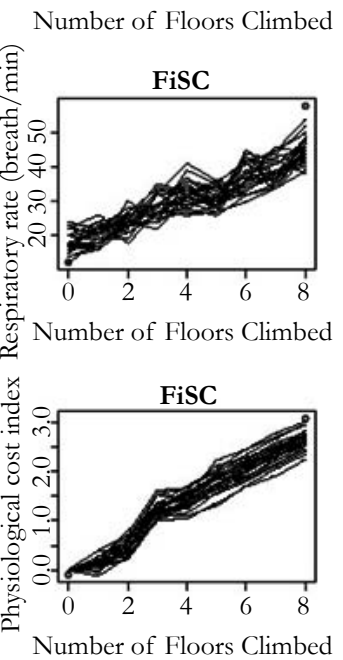


Table 1. Anthropometric, Pulmonary and Maximal Ergometry Parameters.

\begin{tabular}{|l|l|}
\hline \multicolumn{1}{|c|}{ Parameters at rest and exercise } & \multicolumn{1}{c|}{$\begin{array}{c}\text { Active men smokers } \\
\mathbf{N}=\mathbf{2 5}\end{array}$} \\
\hline Age, years & $47.0(45.2 ; 48.0)$ \\
\hline Weight, $\mathrm{kg}$ & $74.1(70.2 ; 80.0)$ \\
\hline Height, $\mathrm{cm}$ & $174(172 ; 177)$ \\
\hline BMI, $\mathrm{kg} / \mathrm{m}^{2}$ & $24.4(23.5 ; 25.7)$ \\
\hline VC L & $5.2(5.0 ; 5.5)$ \\
\hline VC $\%$ & $119.8(114.3 ; 126.2)$ \\
\hline FEV1 L & $3.8(3.7 ; 4.1)$ \\
\hline FEV1 $\%$ & $126.9(121.6 ; 133.9)$ \\
\hline FEV1/VC $\%$ & $73.3(71.7 ; 74.9)$ \\
\hline VO ${ }_{2}$ max $(\mathrm{cycle})(\mathrm{ml} / \mathrm{min})$ & $2449(2350 ; 2681)$ \\
\hline VO ${ }_{2}$ max $(\mathrm{cycle})(\mathrm{ml} /(\mathrm{kg} / \mathrm{min})$ & $34.2(29.8 ; 38.6)$ \\
\hline PWR $(\text { Watts })^{2}$ & $180(180 ; 210)$ \\
\hline
\end{tabular}

Values are presented as medians (IQR); BMI= body mass index; $\mathrm{VC}=$ slow vital capacity; FEV1 = forced expiratory volume in the first sec; $\mathrm{VO}_{2} \max =$ maximal Oxygen consumption; PWR = Peak Work Rate on cycleergometer.

Figure 3. Exertional Dyspnea and Leg Pain as a Function of Flights Climbed.

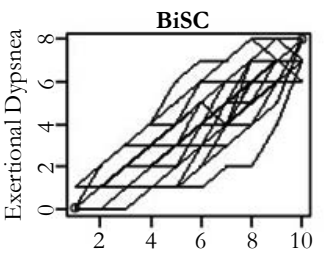

Number of Floors Climbed

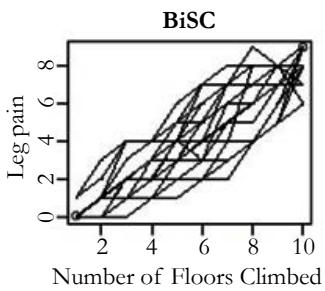

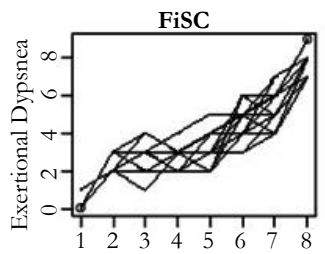

Number of Floors Climbed

FiSC

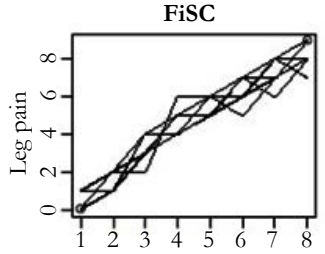

Number of Floors Climbed

Table 2. Stair Climbing Protocols: Reproducibility and Comparisons of Clinical and Physiologic Parameters of Both Maximal Tests at Baseline and after 6 Weeks.

\begin{tabular}{|c|c|c|c|c|c|c|}
\hline \multirow{2}{*}{ Parameters } & \multirow{2}{*}{ Phase } & \multicolumn{2}{|c|}{ BiSC-10 $(n=25)$} & \multicolumn{2}{|c|}{ FiSC $-8(n=25)$} & \multirow{2}{*}{$* * \mathrm{p}$} \\
\hline & & Median (IQR) & $*_{\mathrm{p}}$ & Median (IQR) & $*_{\mathrm{p}}$ & \\
\hline HR (beats/min) & $\begin{array}{l}\text { Baseline } \\
+6 \text { weeks }\end{array}$ & $\begin{array}{l}168(166 ; 170) \\
167(161 ; 170)\end{array}$ & 0.543 & $\begin{array}{l}171(169 ; 174) \\
172(170 ; 174)\end{array}$ & 0.593 & $\begin{array}{l}<.001 \\
<.001\end{array}$ \\
\hline RR (breaths/min) & $\begin{array}{l}\text { Baseline } \\
+6 \text { weeks }\end{array}$ & $\begin{array}{c}48.5(46.2 ; 51.7) \\
49(46 ; 50.7)\end{array}$ & 0.963 & $\begin{array}{c}40.5(39 ; 42.7) \\
45(43 ; 47.7) \\
\end{array}$ & $<.001$ & $\begin{array}{l}<.001 \\
<.001\end{array}$ \\
\hline $\mathrm{SpO}_{2}(\%)$ & $\begin{array}{l}\text { Baseline } \\
+6 \text { weeks }\end{array}$ & $\begin{array}{l}96(96 ; 97) \\
96(96 ; 97)\end{array}$ & 0.868 & $\begin{array}{l}94(94 ; 95) \\
94(93 ; 94)\end{array}$ & 0.004 & $\begin{array}{l}<.001 \\
<.001\end{array}$ \\
\hline ED (Borg scale) & $\begin{array}{l}\text { Baseline } \\
+6 \text { weeks }\end{array}$ & $\begin{array}{l}7(7 ; 7) \\
7(7 ; 8)\end{array}$ & 0.140 & $\begin{array}{c}7(7 ; 8) \\
8(7.25 ; 8)\end{array}$ & 0.001 & $\begin{array}{l}0.209 \\
0.009\end{array}$ \\
\hline $\begin{array}{c}\text { Leg pain } \\
\text { (Borg scale) }\end{array}$ & $\begin{array}{l}\text { Baseline } \\
+6 \text { weeks }\end{array}$ & $\begin{array}{c}8(7.25 ; 8) \\
8(7 ; 8)\end{array}$ & 0.811 & $\begin{array}{l}8(8 ; 9) \\
8(8 ; 9)\end{array}$ & 0.578 & $\begin{array}{l}0.041 \\
<.018\end{array}$ \\
\hline PCI & $\begin{array}{l}\text { Baseline } \\
+6 \text { weeks }\end{array}$ & $\begin{array}{l}2.57(2.48 ; 2.64) \\
2.51(2.39 ; 2.58)\end{array}$ & 0.183 & $\begin{array}{l}2.67(2.49 ; 2.76) \\
2.68(2.56 ; 2.74)\end{array}$ & 0.797 & $\begin{array}{l}0.054 \\
0.001\end{array}$ \\
\hline
\end{tabular}

BiSC-10 = Bilevel intensity stair-climbing protocol for 10 flights of stairs (see text); FiSC- $8=$ Fixed intensity stair-climbing protocol $(8$ flights of stairs); SD = standard deviation; $\mathrm{IQR}=$ interquartile range; $\mathrm{HR}=$ Heart rate; $\mathrm{RR}=$ Respiratory rate; $\mathrm{SpO}_{2}=$ pulse oximeter oxyhemoglobin saturation; ED= Exertional dyspnea; $\mathrm{PCI}=$ Physiological cost index. ${ }^{*} \mathrm{p}$ value is from comparing each protocol initially with the subsequent performance at 6 weeks and between them; the ** $\mathrm{p}$ value compares each parameter of the FiSC- 8 with the corresponding parameter of the BiSC-10 both at baseline, and at six weeks. 
Table 3. Comparison of Blood Pressures and Heart Rates at rest and during Eercises.

\begin{tabular}{|c|c|c|c|}
\hline Rest and exercises $(\mathbf{n}=\mathbf{2 5 )}$ & $\begin{array}{c}\text { Systolic BP } \\
\mathbf{m m H g}\end{array}$ & $\begin{array}{c}\text { Diastolic BP } \\
\mathbf{m m H g}\end{array}$ & $\begin{array}{c}\text { Heart rate } \\
\text { Beats } / \mathbf{m i n}\end{array}$ \\
\hline At rest & $142(138 ; 144)$ & $80(78 ; 82)$ & $84(81 ; 84)$ \\
\hline E1) After $10^{\text {th }}$ floor of BiSC-10 & $165(163 ; 168)$ & $76(75 ; 78)$ & $162(159 ; 164)$ \\
\hline E2) After $8^{\text {th }}$ floor of FiSC-8 & $190(188 ; 194)$ & $84(82 ; 85)$ & $172(170 ; 173)$ \\
\hline E3) After $8^{\text {th }}$ of 10 floors of BiSC-8 & $152(149 ; 154)$ & $74(73 ; 76)$ & $142(140 ; 144)$ \\
\hline E4) After PWR (cycle ergometer) & $180(178 ; 182)$ & $78(77 ; 79)$ & $168(166 ; 169)$ \\
\hline
\end{tabular}

$\mathrm{E}=$ Exercise BP = Blood Pressure; BiSC-10 = Bi-level intensity stair-climbing 10 floors; FiSC = Fixed intensity stair-climbing for 8 floors; BiSC-8 = Bi-level intensity stair-climbing over 8 floors; PWR = Peak Work Rate. Data are medians (IQR)

Table 4. Post - Study Stair Climbing Questionnaire.

\begin{tabular}{|c|c|c|c|}
\hline \multirow{2}{*}{$\begin{array}{c}\text { Question Posed } \\
(\mathbf{N}=\mathbf{2 5})\end{array}$} & "Yes" Answer Count & \multirow{2}{*}{ p } \\
\cline { 2 - 3 } & BiSC-10 & FiSC-8 & \\
\hline Do you consider this test rapid (in time)? & $25(100)$ & $19(73.1)$ & 0.050 \\
\hline Do you consider this test reproducible (at home)? & $25(100)$ & $23(88.5)$ & 0.235 \\
\hline Do you consider this test safe? & $25(100)$ & $18(69.2)$ & 0.040 \\
\hline Do you consider this test easy to understand? & $25(100)$ & $24(96.3)$ & 0.490 \\
\hline Do you consider this test maximally intense? & $25(100)$ & $25(100)$ & - \\
\hline Do you consider this test home use friendly? & $25(100)$ & $8(30.8)$ & $<.001$ \\
\hline Do you consider this test economic? & $25(100)$ & $25(100)$ & - \\
\hline
\end{tabular}

BiSC-10 = Bi-level intensity stairs climbing over 10 floors; FiSC-8 = Fixed intensity stairs climbing over 8 floors. Data are frequencies $(\%)$

tocol also had a desirable cardiovascular profile $[7,11]$ and was best tolerated.

While there are no published standardized physiologic studies of bi-level stair-climbing, a best approximation might be from studies of bi-level Square-Wave Endurance Exercise Training (SWEET) which is 45 minutes of bi-level cycle-ergometry [5, 11, 21, 23]. The SWEET is very well tolerated because its short 1 min cycles of maximal exertion (i.e., $60 \%$ of $\mathrm{VO}_{2}$ max) do not provoke intolerable dyspnea or leg pain. Using the SWEET protocol, at the $45^{\text {th }}$ min with maximal heart rate, measured lactic acidosis was only $50 \%$ of that observed at $\mathrm{VO}_{2}$ max and arterial hydrogen ion concentration remained around normal resting values $[5,11,21]$.

Similar to SWEET [21, 23], BiSC involves brief intervals of positive work (i.e., 12 seconds of ascend), negative work (i.e., 8 seconds of descend) and produces a high respiratory rate (Table 2) yet at lower heart rates than previously reported for exercise to $\mathrm{VO}_{2}$ max or PWR (Table 3) [5, 11, 27-29].

Six minute walks, too, are often used to estimate aerobic exercise capacity $[31,34]$. Continuous walking has also been recommended by some health professionals for endurance training [6]. However, 6 minute walk studies have up to $42 \%$ variability [31], and have not been standardized for endurance training.

Limitations of this study include its small sample size and homogeneous male population so the results cannot be generalized to females. A confounding factor for standardizing stair climbing energy consumption was the use of handrails which have been reported to have prolonged total treadmill time and can result in an overestimation of attainable stair climbing $\mathrm{VO}_{2} \max$ [30-33]. While the actual $\mathrm{VO}_{2}$ max can be significantly reduced by handrail use in submaximal exercise [32], it has not been reported to be affected by maximal exertion [30]. Manfre et al., [30]. measured oxygen consumption while 11 healthy men performed two symptom-limited treadmill tests, one with limited handrail support and one prohibiting contact with the front handrail [30]. There was no significant $(\mathrm{p} \leq 0.05)$ difference between the measured $\mathrm{VO}_{2}$ max and percent of predicted maximal heart rates for both protocols. The few occasions our subjects used handrails were transient and limited to the FiSC protocol.

\section{Conclusion}

The protocol of exercise climbing stairs with two levels one flight is more practical, for the subject and the specialized Staff that survey the subjective and cardiorespiratory responses, and is better tolerated than that of the FiSC.

\section{Acknowledgement}

We thank Lahoucine Benhamgar, $\mathrm{PhD}$, epidemiologist researcher, for scientific and statistical advising, assistance and constructive criticism throughout the study; Jean Lonsdorfer MD, PhD, Maria Angeles Montoliu, MD, PhD, María Escudero, MD, for clinical help and advice; Elisabeth Polu, Encarnación Abril, Mari Carmen Lareo and Andrés Aranda PT, for their participation in the clini- 
cal trial and implementation of physical protocol techniques; Juan Verona for help with graphics and drawings; and the 25 smokers who faithfully followed the complete protocol.

\section{References}

[1]. Sword, David O (2012) Exercise as a Management Strategy for the Overweight and Obese. Strength and Conditioning J. 34(5): 47-55.

[2]. Flegal KM, Carroll MD, Kit BK, Ogden CL (2010) Prevalence of obesity and trends in the distribution of body mass index among US adults, 19992010. JAMA. 307(5): 491-497.

[3]. Varga J, Porszasz J, Boda K, Casaburi R, Somfay A (2007) Supervised high intensity continuous and interval training vs. self-paced training in COPD. Respir Med. 101(11): 2297-2304.

[4]. Casaburi R, Patessio A, Ioli F, Zanaboni S, Donner CF, et al., (1991) Reduction in exercise lactic acidosis and ventilation as a result of exercise training in patients with obstructive lung disease. Am Rev Respir Dis. 143(1): 9-18.

[5]. Gimenez M, Saavedra P, Martin N, Polu JM, López D, et al., (2012) Bi-level exercise training and directed breathing relieves Exertional Dyspnea for male smokers. Am J Phys Med Rehabil. 91(10): 836-845.

[6]. World Health Organization (2010) Global Recommendations on physical Activity for Health.

[7]. Gimenez M, Saavedra P, Martin N, Lantarón EM, Polu E, et al., (2014) Two Step Stool Aerobic Training for Smokers: Am J Phys Med Rehab. 93(7): 1-9.

[8]. Charloux A, Brunelli A, Bolliger CT, Rocco G, Varela G, et al., (2009) Lung function evaluation before surgery in lung cancer patients: how are recent advances put into practice? A survey among members of the European Society of Thoracic Surgeons (ESTS) and of the Thoracic Oncology Section of the European Respiratory Society (ERS). Interact Cardiovasc Thorac Surg. 9(6): 925-31.

[9]. Brunelli A, Charloux A, Bolliger CT, Rocco G, Sculier J-P, et al., (2009) ERS/ESTS clinical guidelines on fitness for radical therapy in lung cancer patients (surgery and chemo-radiotherapy) Eur Respir J. 34(1): 17-41.

[10]. Quanger PH, Tammeling GI, Cotes JE, Pedersen OF , Peslin R, et al., (1993) Lung volumes and forced ventilatory flows. Report working party standardization of lung function tests, European Community for Steel and Coal. Official statement of the European Respiratory Society. Eur Respir J. 16(6): 5-40.

[11]. Gimenez Manuel (1992) L'EpreuveenCréneaux pour l'entrainement et la mesure de l'endurance : I) EffetsPhysiologiques et Biochimiques ; II) Application chez l'Homme normal et Handicapé. ThèseUniversité Nancy I ;deux volumes:1) Texte, et 2) Figures et Tableaux, 1060 pages.

[12]. Borg GA (1982) Psychophysical bases of perceived exertion. Med Sci Sports Exerc. 14(5): 377-81.

[13]. Laird NM, Ware JH (1982) Random-effects models for longitudinal data. Biometrics. 38(4): 963-74.

[14]. R Core Team (2013) R: A language and environment for statistical computing. R Foundation for Statistical Computing, Vienna, Austria.

[15]. Blackie SP, Fairbarn MS, Wilcox PG, Morrison NJ, Pardy RL (1991) Normal values and ranges for ventilation and breathing pattern at maximal exercise. Chest. 100(1): 136-42.

[16]. Bergstrom A, Andersson B, Edner M, Nylander E, Persson H, et al., (2004) Effect of carvedilol on diastolic function in patients with diastolic heart failure and preserved systolic function. Results of the Swedish Doppler-echocardiographic study (SWEDIC). Eur J Heart Fail. 6(4): 453-61.

[17]. Pollock M, Roa J, Benditt J, Celli B (1993) Estimation of ventilatory reserve by stair climbing: a study in patients with chronic airflow obstruction. Chest. 104(5): $1378-1383$

[18]. Koegelenberg CFN, Diacon AH, Irani S, Bolliger CT (2008) Stair climbing in the functional assessment of lung resection candidates. Respiration .
75(4): 374-379.

[19]. Swinburne CR, Wakefield JM, Jones PW (1985) Performance, ventilation, and oxygen consumption in three different types of exercise tests in patients with chronic obstructive lung disease. Thorax . 40(8): 581-86.

[20]. Brunelli A, Al Refai M, Monteverde M, Borri A, Salati M, et al., (2002) Stair climbing test predict cardiopulmonary complications after lung resection. Chest . 121(4): 1106-1110.

[21]. Gimenez M, Servera E, Saunier C, Lacoste J (1982) Square-Wave Endurance Exercise Test (SWEET) for training and assessment in trained and untrained subjects. II: Blood gases and acid-base balance. Eur J Appl Physiol. 49(3): 369-77.

[22]. Gimenez M, Cereceda V, Teculescu D, Aug F, Laxenaire MC (1982) SquareWave Endurance Exercise Test (SWEET) for training and assessment in trained and untrained subjects. III: Effect on $\mathrm{VO} 2 \mathrm{max}$ and maximal ventilation. Eur J Appl Physiol. 49(3): 379-87.

[23]. Gimenez M, Abril E, Rodríguez F, Buono M (2004) Effects of Sweetraining on healthy, trained and untrained subjects and chronic pulmonary patients. Prevention and Rehabilitation in Chronic Respiratory Pathology. 2nd (Edn), Madrid, Panamericana. 103-117.

[24]. Lonsdorfer J, Lampert E, Mettauer B, Hoppeler H, Frey M, et al., (1992) Physical fitness after cardiac transplantation: A proposal for an endurance training program and assessment. Sci Sports. 7(1): 39-44.

[25]. Mettauer B, Lampert E, Schnedecker B, Bogui P, Lonsdorfer J (1993) A short endurance training program increases the physical fitness of heart transplant recipients. Sci Sports. 8(1): 25-6.

[26]. Lampert E, Mettauer B, Lonsdorfer J (1994) Effects of "encreneaux" training on the late physical disability of cardiac grafts. Méd Sport (Paris). 68:142-44.

[27]. Gimenez M, Abril E, Chabot F (1994) Strategies for physical and vulatory training of patients before and after transplant. Méd Sport. 68: 146-56

[28]. Hermansen L, Osnes JB (1972) Blood and muscle $\mathrm{pH}$ after maximal exercise in man. J Appl Physiol. 32(3): 304-8.

[29]. Gimenez M, Hennequin R, Horsky P, Colas T, Saunier C (1974) Evolution of the lactacidemia of the acid-base and electrolytic equilibrium in the case of a 20-minute rectangular rectangular muscular exercise in humans with different loads and the Maximal Power Support. Bull Physiopathol Resp. 10: 463-80.

[30]. Manfre M, Yu Guan-Hiok, Varma AA, Mallis GI, Kearney K, et al., (1994) The Effect of Limited Handrail Support on Total Treadmill Time and the Prediction of V02max. Clin Cardiol 17(8): 445-450.

[31]. Berling J, Foster C, Gibson M, Doberstein S, Porcari J (2006) The effect of handrail support on oxygen uptake during steady-state treadmill exercise. J Cardiopulmonary Rehab. 26(6): 391-4.

[32]. Rimmer JH, Rauworth AE, Wang EC, Nicola T, Hill B (2009) A preliminary study to examine the effects of aerobic and therapeutic (no aerobic) exercise on cardio respiratory fitness and coronary risk reduction in stroke survivors. Arch Phys Med Rehab. 90(3): 407-12.

[33]. National Center for Chronic Disease Prevention and Health Promotion and Centers for Disease Control and Prevention (1996) Physical Activity and Health: A Report of the Surgeon General, June 2009.

[34]. Nikolić I, Majerić-Kogler V, Plavec D, Maloča I, Slobodnjak Z (2008) Stairs Climbing Test with Pulse Oximetry as Predictor of Early Postoperative Complications in Functionally Impaired Patients with Lung Cancer and Elective Lung Surgery: Prospective Trial of Consecutive series of patients. Croat Med J. 49(1): 50-57.

[35]. Casanova C, Celli BR, Barria P, Casas A, Cote C, et al., (2011) The 6-min walk distance in healthy subjects: reference standards from seven countries. Eur Respir J. 37(1): 150-6.

[36]. Chetta A, Pisi G, Aiello M, Zani P, Oliveri D (2009) The walking capacity assessment in the respiratory patient. Thematic Review series Respiration. 77(4): 361-7. 